\title{
Curriculum Design and Delivery for E-Government Knowledge Transfer in a Cross Cultural Environment: The Bangladesh Experience
}

\author{
Ahmed Imran ${ }^{1}$, Shirley Gregor ${ }^{2}$, and Tim Turner ${ }^{1}$ \\ ${ }^{1}$ UNSW Canberra at the Australian Defence Force Academy, Australia \\ \{a.imran, t.turner\} @adfa.edu.au \\ ${ }^{2}$ Australian National University, Canberra, Australia \\ Shirley.gregor@anu.edu.au
}

\begin{abstract}
This paper describes a successful intervention to facilitate the adoption of e-government in a least developed country. The action design research project adopted an unusual approach to facilitating e-government based on earlier grounded research that identified particular underlying inhibitors to adoption. In this case, the need to increase the knowledge of the Bangladeshi public servants to the potential and approaches of e-government was a higher priority than attempting any specific e-government project implementation. A formal education program has been established that is available to all Bangladeshi public servants through institutional training. The project's approach and the lessons learned in its delivery provide a useful framework for other e-government interventions in least developed countries.
\end{abstract}

Keywords: ICT4D, E-government, Cross culture, Knowledge transfer, Curriculum design.

\section{$1 \quad$ Introduction}

In the 21st century's information-intensive economy and society, "knowledge" is considered the most precious commodity, and knowledge transfer initiatives can make significant differences in under privileged societies (Kefela 2010). The e-government capacity building project described here aimed at building knowledge of the benefits of information and communication technology (ICT) for decision making and work practices among public sector leaders. This two year long project involved action design research (ADR) (Iivari and Venable 2009, Sein, Henfridsson et al. 2011) and application of reflective practices (Loughran 2002) in developing an educational curriculum from the ground up. The intervention, with multi-level stakeholders from two countries with different socio-economic and cultural backgrounds, provided rich insights and lessons on cross-cultural design issues, which could be useful for practitioners and researchers working in developing countries. The paper first outlines the project, followed by its rationale and background, discusses the key challenges, lessons learned and implications for the future. 


\section{The Project}

In 2008, based on existing research work, the first phase of an e-government capacity building project in Bangladesh was launched with the help of the competitive Public Service Linkage Grant (PSLP) from the AusAID (Imran, Gregor et al. 2009). The broad objectives of the project were to improve transparency and efficiency in the public sector in Bangladesh with enhanced benefits to citizens. This activity addressed an important problem area identified through prior research, a lack of fundamental knowledge and awareness of the strategic use and implications of ICT systems for government business processes; a major barrier to e-government adoption in Bangladesh (Imran and Gregor 2010). This lack of knowledge inhibited responses to a range of other barriers such as poor infrastructure, low socio-economic conditions and lack of leadership. Accordingly, a two phase intervention was planned. In 2008, the first phase aimed to: (1) build a long-term strategy for successful e-government adoption, and (2) overcome knowledge barriers by short-burst specially designed training packages for senior decision makers within the public services.

In 2010, the second phase of the intervention was designed building upon the achievements of the initial activity (Imran, Turner et al. 2008) as a next step to institutionalise a more robust knowledge base amongst the public sector officials in Bangladesh. The Bangladesh Public Administration Training Centre (BPATC) was chosen as the counterpart organisation. BPATC delivers training for both new and more senior government officers from all cadres and services of the government, including police, customs and other affiliated organisations. In the past the only ICT-related course at BPATC, "ICT and E-governance", had covered only introductory and basic skills training for ICT and lacked quality and purpose.

To achieve the overarching goal, the activity focused on building a long-term institutional capacity through a well-designed sustainable knowledge building scheme. A techno-centric approach in the past has been the cause of failures of many egovernment initiatives in developing countries (Heeks 2003). The approach in our project, in contrast, emphasized 'human-ware' as the precondition or major driver for successful adoption of e-government. Often, managers' lack of motivation, fear of the unknown, resistance to change and negative attitudes are significant obstacles for such innovation (Imran and Gregor 2010).

\subsection{Program Purpose}

This program was especially designed to give familiarity with the technical and managerial processes required to successfully execute e-government projects and also to highlight the key aspects of successful project management practices in the context of socio-cultural and organisational complexity. The curriculum provides an opportunity to consider real-life experiences through case studies from developed as well as developing countries. The trainee officers are expected to gather clear knowledge of how e-government operates, an understanding of the roles they could be asked to fill, and insight into the combination of managerial, analytic, and technical knowledge they need if they are to handle e-government projects effectively and with confidence.

The program aimed to develop competency in e-government management focusing on three major areas: 
- Knowledge of the use ICT and its benefits in e-government in an LDC

- Knowledge of essential ICT systems and technology;

- Knowledge of strategic ICT management.

\subsection{Course Design}

The course was developed following an outcomes-based approach to learning, where learning objectives are specified for each learning component prior to its development. This approach allows both instructors and students to be aware of what is expected from each other and also to design the assessments. In specifying learning objectives, Bloom's taxonomy of learning objectives (Bloom 1956) that was enhanced by Anderson et al. (Anderson, Krathwohl et al. 2001) was used as the primary guide. This taxonomy has six levels of learning and each level (Remembering, Understanding, Applying, Analysis, Evaluating and Creating) has "action" words associated with it, which indicate the explicit outcomes expected in terms of learning.

One of the underlying objectives of the program was to help the public sector officials to develop their capacity to recognise how they could use e-government to create a positive impact in society. Realizing this objective required a series of reflections from different stakeholders that focused on understanding the broader issue of egovernment implementation and the culturally-specific issues of the Bangladesh Public Sector and broader society. These reflections were followed by careful crafting of the course. The course design built on the work in the earlier phase, particularly the short-burst training course, because research has shown that such an approach is effective and relevant in addressing the complexity of embedding innovations in the context of a least developing country (Bangladesh). The curriculum has been designed to harmonise with the counterpart's capabilities and meet priority learning needs of public servants. Training material for use in classroom-based teaching included presentation material, individual, small-group, and whole-group exercises, case studies and review questions (with answers), a short quiz and a long quiz (both with answers), and an instructor's manual (i.e. lesson plan).

\section{Project Output/ Deliveries}

\subsection{The "E-Government Management" Training Package}

A full-fledged university standard course (equivalent to a 13 week semester long course in Australian terms) was designed through a series of grounded studies and consultations with the counterpart organisation, tertiary education designers, relevant experts and stakeholders. The primary audience for this course is government officers in developing countries who have some managerial experience (mid-level). Accordingly, the perspectives of practising managers were incorporated in the course. It is expected that participants may come from different fields (such as arts, engineering, science, management) and will have some tertiary education, plus basic IT skills and knowledge (for example, word-processing and email). 


\subsection{A Text Book on E-Government Management for Developing Countries}

A preliminary version of a textbook on e-government in least developed countries (in general, not Bangladesh alone) has been prepared, which follows the format of existing quality texts used in Management of IT courses at the post-graduate level. The final text book is a significant output of the activity as it is the first of its kind for developing countries; consisting of four major parts and sixteen chapters. This text book will be reused by BPATC for ongoing e-government management courses as a main text book and guide to the training.

\section{$4 \quad$ Project Evaluation and Benefits}

The project activities included two phases of evaluation, one before the course and one after the course, using a combination of qualitative and quantitative methods. Below is a discussion on the benefits of the course.

\subsection{Managers in the Public Sector Who Have Completed the Training Program Have Increased Knowledge of How to Oversee the Use of ICT (E-Government) in the Public Sector}

This was the significant outcome and major objective of the activity. Participating officers had increased knowledge and confidence, which was clearly reflected in the evaluation carried out after the course. It was further evident through their initiatives in their workplace after the expiry of the course (Source: Students reflection during certificate award ceremony after six months of the 7th ITEG Course, Date 8th Jan 2012). Some participants played a 'champion' role in initiating actual e-government proposals and projects and some had made policy contributions in their respective organisations which were publicly shared in the certificate award ceremony.

\subsection{A High-Quality and Research-Based Training Course on E-Government Management}

The newly developed course is a high-quality first of its kind for developing countries that meets the requirements for public sector officials. This paradigm shift has significantly improved the standard, reputation and outcome of the course. The capacity of BPATC was strengthened as it now has a well-designed educational program available for delivery in an area that is essential for the modernization of government.

Before the intervention, staff at BPATC indicated that they see a strong need for developing public sector managers' knowledge of ICT, but they had neither the expertise nor the resources to develop relevant and required curriculum. The offering of the program to train local educators on program delivery as a practical train-the-trainer course has strengthened in-house capacity to run this course after the intervention. Staff at BPATC had the opportunity for personal development by participating in the development and delivery of a leading-edge and innovative program.

Three offerings of the program occurred, with the third offering undertaken by BPATC instructors alone. Each offering received positive ratings by participants on completion of the course. Follow-up interviews with participants after the program 
showed materials were assimilated and were being applied in practice. According to one participant,

It changed my vision, it cleared my idea about e-government, now I'm confident and motivated for e-government. It will give me an opportunity to introduce ICT in my organisation (Student feedback, $2^{\text {nd }}$ E-government Management Course, 08 January, 2011).

\subsection{A Targeted Textbook for E-Government in Least Developed Countries}

Some of the participants of this course were appointed to new positions related to new or existing e-government projects. The textbook, which has been shared amongst many stakeholders, is used as a companion, reference book and for consultation. Use of course material was evident beyond the class room environment.

Follow-up interviews with participants after the program show the textbook is in regular use and is providing assistance in managing e-government projects. According to the Rector of BPATC,

The experience of the last few years has shown that there is a strong hope in initiating change in officers' through information technology and $e$ governance. With the knowledge and expertise gained from the course the vision of good governance and true citizen engagement can become a reality. (Message from the Rector, BPATC at Students' Magazine of $2^{\text {nd }} E$ government Management course, 08 January, 2011)

In addition to the planned output, the project has also contributed in other areas in the form of unanticipated benefits. For example, the application of modern pedagogy, assessment and curriculum design in the course provided much insight and knowledge to the course officials and the instructors who could apply those in other courses within the BPATC. Evidence shows that they are doing this. The project has increased Australia's reputation in Bangladesh through knowledge sharing. Australia's wholeof-government approach to the LDC's development problem in the partner country was well-received. The experience and knowledge from the Australian whole-ofgovernment approach has huge potential in the public sector, with capacity building possible more widely through knowledge transfer.

\section{$5 \quad$ Challenges Faced}

\subsection{Contextualisation of Contents}

One of the greatest challenges was to properly manage the context of the educational material. Many of the concepts and topics used in mature IT organisations in developed countries are difficult to translate or contextualise in the nascent environment of the many developing countries that are at the early stages of IT adoption. Use of terms, which have different connotations in different context and cultures, was particularly noticeable (e.g. speaking of a "business" case when discussing government activity).

Significant attention to these issues was needed to meet cultural norms and customs including the use of particular presentation techniques and the careful use of English language and tone to suit the target audiences in the best possible manner. 
Effort was made to sift the important from the unimportant and to pick the right tone for target audiences to avoid burdening them too much with information that was not particularly relevant or was too technical or specific for their use.

\subsection{Generating Interest of the Participants}

Student participation was the key to success. Maintaining student interest in a newlydeveloped subject was challenging, particularly as it was addressing an area where they had a self-reported lack of knowledge. Active participation was achieved through good application of pedagogy which included case discussions, projects, video clips, clear power point presentations and relevant contents.

\subsection{Addressing the Sustainability Issue}

Sustainability was a key element in this activity. The activity and its connection to the 2008 project is a demonstration of commitment to sustainability by the project team and sponsor, something frequently noted by its absence in other international donor initiatives. Research shows many of the e-government initiatives in developing countries fail due to the 'one-off type' and 'techno centric' approaches (Heeks 2003). This activity has addressed those deficiencies, the knowledge of which slowly contributing to the future projects, where citizens will be able to reap the actual benefit.

\subsection{Endorsement of the Curriculum}

Endorsement of the course and its proper application in replacing the existing offering in the annual training schedule was most challenging. This was also one of the great achievements. Changing curriculum and the name of the course to "E-government Management" through the high-level standing committee of the BPATC was a critical endorsement of the move to a new approach. This outcome was ensured through discussion with the authority concerned in every phase of the design stage.

\subsection{Ownership and Maintaining the Interest}

A further risk minimization strategy was adopted by keeping the counterpart stakeholders involved in the project at all steps so that a feeling of ownership was developed. It was important to maintain the interest of the stakeholders in the program through regular commitments, communications and timely response and delivery of programs. A preliminary road test was carried out with the development team and members from the counterpart organisation to carry out a requirement analysis.

\subsection{Maintenance of the Integrity of the Program}

Over the repeated offerings of the course within the timeframe of the project, there was a tendency to mix in material from other courses within the BPATC program or for modifications to the content to be made by some external instructors to have material that they were more comfortable to teach. However, the project team was diligent to maintain the designed content and delivery so as not to break the integrity of the program, which could have jeopardised the outcomes and overall learning 
objectives. We tried to make the instructors understand the importance of keeping the program intact, not only to maintain the chronological understanding of the issues but also in attaining external university recognition in future.

\subsection{Transfer of Officials}

Transfer of officials and instructors who were already trained resulted in the need to train others during the time of the project. These transfers meant duplicated effort that had not been foreseen. However, the effort needed to maintain the base of trained instructors was covered by other contingency plans.

\subsection{Political Instability}

Instability in the political environment is an inherent problem in many LDCs beyond the control and scope of individual projects. Political instability and unrest often hindered the smooth running of the activity, which also created uncertainty for the future. Because of the political instability, a clear, coherent strategy cannot be maintained within the ICT sector. It seems that every five years a new party comes to power and changes all previous plans and strategies. This is particularly true in complex, leading-edge agenda, such as IT adoption and e-government exploitation.

\subsection{Dealing with Bureaucracy}

Dealing with bureaucracy and public sector officials in a developing country is always a challenging task, because of the hierarchy and complexities of the procedures involved, especially in implementing an applied research project from overseas. However, this challenge has been met through connections established through one team member's previous working experience in the Bangladesh Government.

\subsection{Demanding Time Schedule}

Managing the project's schedule and the commitment of all stakeholders to match the BPATC program calendar was also challenging. However, through all-out support and dedication from all involved the project worked out well. The significant time spent on negotiation and correspondences between BPATC and the project team on training, coordination and financial matters at times was extremely demanding.

\section{$6 \quad$ Lessons Learned}

Lessons learned from this project will be particularly relevant and useful for egovernment interventions in other developing countries. Methodologically, the study provides an example of ADR in an unusual context, an intervention that is aimed at alleviating a situation at a national level. As e-government is frequently aimed at whole-of-government view, or at least cross-government-agency scope, a positive example of supra-organisational intervention is valuable.

The project has also yielded significant outcomes in the area of new knowledge building. Critical reflection has established a number of design principles for a "Sweet 
Spot Change (SSC) strategy" (Gregor, Imran et al. 2010) for interventions of this type, with the most important principle being to first identify a "sweet spot", a point of maximum leverage, and then act on it. In e-government, the sweet spot may not be in the immediately expected areas of technology or business processes. Particularly in developing countries, the 'people' element of best practice e-government approaches may be the most challenging, and rewarding area.

The project also demonstrates that e-government in a least developed country is greatly facilitated by the inclusion of a leading participant with a working experience, a well-developed reputation and trust in the context of the public sector environment in the LDC. The 'native' insight was instrumental in addressing the culturallysensitive challenges and also in capturing the underlying important issues that are often overlooked. Good access and personal liaison with the stakeholders of ICT in the country, some national policy makers, and Government agencies were also important.

Another lesson learned was that good practice guides from other countries (case studies, best practices) can be effective in achieving learning outcomes, when adapted to suit the local context. The experience and formalisations of the Australian Government's experience in e-government, in this case, were an excellent starting point for a properly-contextualised delivery of the concepts of e-government to Bangladeshi public servants. Similarly, having the support of two of Australia's leading universities, with their capable researchers to work as a team, provided the means to deliver proper course development skills-transfer to the BPATC, the peak training agency for Bangladesh's public service.

\section{Conclusion}

E-government properly implemented offers the potential for substantial benefits to least developed countries, particularly at a whole-of-government level. The project outlined here demonstrates that a thoughtfully conducted project that builds on developed country e-government experience but is sensitive to the cultural and environmental factors present in the least developed recipient country can be very effective.

It was evident from many of the evaluation responses collected after each offering of the course that training of this nature was something new to the participants as it addressed practical issues and needs of the students rather than more conventional 'factory-made' training. Developing and delivering the course was also a rewarding learning experience for the researchers/designers, to be part of such international work aiming to contribute to the societal benefit of a disadvantaged society.

The training package and the text book prepared for Bangladesh address issues and concerns common to other LDCs in the field of e-government. A huge potential exists across many developing countries in the world to benefit from replicating this program with some modification to the country context.

There are a number of potential follow-on activities that can be undertaken based on the success of this activity. For example, offering similar e-government programs and training to other developing countries, expanding and developing longer-term training for the government officers of Bangladesh and elsewhere, and through wider dissemination of the e-government management textbook. Interest shown by other 
organisations affiliated with civil services, universities and IT industry bodies in other least developed countries is encouraging.

Acknowledgements. The support of a number of organizations is gratefully acknowledged, especially AusAID, the Australian Agency for International Development, which was the primary funding body. Support was also provided by the School of Accounting and Business Information Systems at the Australian National University (ANU) and by the Bangladesh Public Administration Training Centre (BPATC). We also acknowledge the students, faculty members and management of BPATC who were directly and indirectly engaged in developing and improving the curriculum.

\section{References}

Anderson, L.W., Krathwohl, D.R., Airasian, P.W., Cruikshank, K.A., Mayer, R.E., Pintrich, P.R., Raths, J., Wittrock, M.C. (eds.): A Taxonomy for Learning, Teaching, and Assessing: A Revision of Bloom's Taxonomy of Educational Objectives. Addison Wesley Longman, Inc., New York (2001)

Bloom, B.S.: Taxonomy of Educational Objectives; The Classification of Educational Goals. Susan Fauer Company (1956)

Gregor, S., Imran, A., Turner, T.: Designing for a 'Sweet Spot' in an Intervention in a Least Developed Country: The Case of e-Government in Bangladesh. In: Proceedings of the Third Annual SIG Globdev Workshop. Association for Information Systems, Special Interest Group on ICT and Global Development, St. Louis, USA (December 2010)

Heeks, R.: Most eGovernment-for-Development Projects Fail: How Can Risks be Reduced? IDPM i-Government working paper no.14. UK, University of Manchester (2003)

Iivari, J., Venable, J.: Action Research and Design Science Research - Seemingly similar but decisively dissimilar. In: 17th European Conference on Information Systems, Verona, Italy (2009)

Imran, A., Gregor, S.: Uncovering the Hidden Issues in e-Government Adoption in a Least Developed Country: The Case of Bangladesh. Journal of Global Information Management 18(2), 30-56 (2010)

Imran, A., Gregor, S., Turner, T.: eGovernment Capacity Building through Knowledge Transfer and Best Practice Development in Bangladesh. In: 10th International Conference on Social Implications of Computers in Developing Countries. IFIP. Dubai School of Governmnet, Dubai (2009)

Imran, A., Turner, T., Gregor, S.: Educate to Innovate - Fast Tracking ICT Management Capabilities Amongst the Key Government Officials for eGovernment Implementation in Bangladesh. In: SIG GlobDev Workshop, Paris, France (2008)

Kefela, G.T.: Knowledge-based economy and society has become a vital commodity to countries. International NGO Journal 5(7), 160-166 (2010)

Loughran, J.: Effective Reflective Practice: In Search of Meaning in Learning about Teaching. Journal of Teacher Education 53(1), 33-43 (2002)

Sein, M.K., Henfridsson, O., Purao, S., Rossi, M., Lindgren, R.: Action Design Research. MIS Quarterly 35(1), 37-56 (2011) 